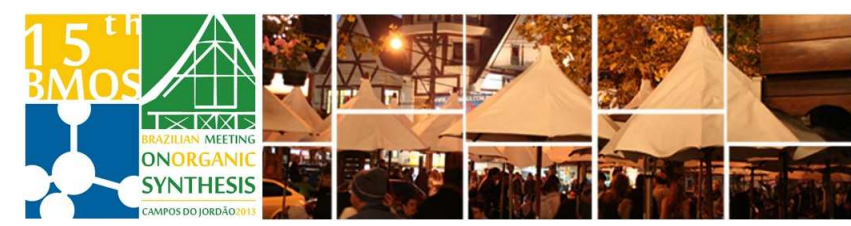

\title{
Synthesis of polisubstituted 1,3-azadienes from enaminones
}

\author{
Monique F. Marques ${ }^{1^{*}}$, Silvio Cunha ${ }^{2}$ \\ ${ }^{1}$ Universidade Federal de Goiás - Instituto de Química, Campus Samambaia, 74001-970, Goiânia-GO \\ ${ }^{2}$ Universidade Federal da Bahia, Instituto de Química and Instituto Nacional de Ciência e Tecnologia em \\ Energia e Ambiente, Universidade Federal da Bahia, Campus de Ondina, Salvador, BA, 40170-290, Brasil. \\ *nique2405@gmail.com
}

Keywords: enaminones, 1,3-azadienes, acetic anhydride

\section{INTRODUCTION}

Azadienes are considered useful building blocks to the synthesis of six-membered heterocyclic cores, ${ }^{1}$ mainly through the hetero Diels-Alder reaction. ${ }^{2}$ Olefination reactions such as Wittig's, Julia's, and Peterson's are normally employed in order to obtain this class of compounds. As part of the reactivity study of azoenaminones (1) prepared by our research group, such compounds were treated with diverse electrophiles. Herein we present our results concerning the synthesis of 1,3-azadienes through acetylation reaction of azoenaminones, performed in mild conditions and with very good yields.

\section{RESULTS AND DISCUSSION}

All the reactions were performed in acetic anhydride as solvent at room temperature, for 24 hours, and triethylamine (TEA) as a base. The products, obtained as a precipitate, were washed with ethyl ether for purification.

When acyclic azoenaminones (1) were reacted with acetic anhydride (2), an acetylation reactions occurred, and 1,3-azadienes (1a and 1 $\mathbf{b}$ ) were obtained in excellent to good yields (Figure 1).

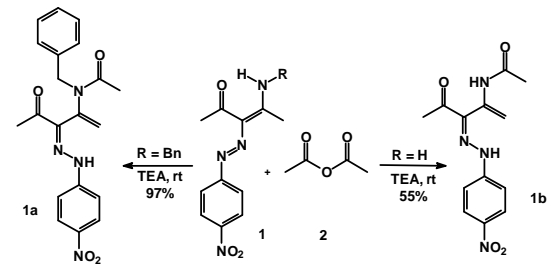

Figure 1. 1,3-Azadienes obtained from acyclic enaminones

In order to increase the scope of the methodology, reactions were carried out with heterocyclic azoenaminones. In these reactions, 1,3-azadienes were obtained through the insertion of a double bond inside the enaminone ring (Figure 2). Table 1 shows the results for the five-membered enaminones 3.

High yields were obtained from azoenaminones derived from diazonium salts with electron withdrawing groups (4a, $\mathbf{4 b}$ and $\mathbf{4 c}$ ), probably due to a more efficient conjugation of the $\pi$ electrons of the azoenaminone moiety. The presence of an electron donor methyl group decreases the yield of the reaction (4d). The proposed mechanism for this reaction involves the nucleophilic attack of nitrogen from the azohydrazone tautomer to the carbonyl group of the acetic anhydride, followed by the removal of a proton by the base present in the reaction medium, leading to the products (Figure 3).



Figure 2. 1,3-azadienes from cyclic enaminones.

Table 1. Yields obtained for the azadienes 4a-d

\begin{tabular}{cll}
\hline Reagent/Product & \multicolumn{1}{c}{ Substituents } & Yields \\
\hline $3 a / 4 a$ & $\mathrm{R}^{1}=\mathrm{Cl} ; \mathrm{R}^{2}=\mathrm{H}$ & $91 \%$ \\
$3 \mathrm{~b} / 4 \mathrm{~b}$ & $\mathrm{R}^{1}=\mathrm{NO}_{2} ; \mathrm{R}^{2}=\mathrm{H}$ & $83 \%$ \\
$3 \mathrm{c} / 4 \mathrm{c}$ & $\mathrm{R}^{1}=\mathrm{Cl} ; \mathrm{R}^{2}=\mathrm{NO}_{2}$ & $73 \%$ \\
$3 \mathrm{~d} / 4 \mathrm{~d}$ & $\mathrm{R}^{1}=\mathrm{Me} ; \mathrm{R}^{2}=\mathrm{H}$ & $49 \%$ \\
\hline
\end{tabular}

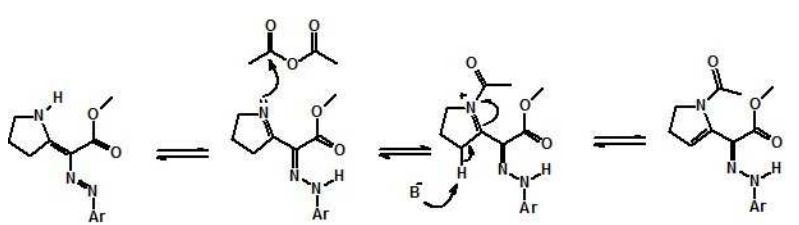

Figure 3. Proposed mechanism.

\section{CONCLUSION}

A new route to the synthesis of 1,3-azadienes was developed, based on mild conditions with to very good yields.

\section{ACKNOWLEDGEMENTS}

The authors thank CNPq, CAPES, INCT and FAPESB for the financial support.

\section{REFERENCES}

Jayakumar, S.; Ishar, M.P.S.; Mahajan, M.P. Tetrahedron 2002, 58, 379

2 Barluenga, J.; Aznar, F.; Fustero, S.; Tomás, M. Pure \& Appl. Chem. 1990, 62, 1956. 